\title{
Combate à COVID-19 sob o federalismo bolsonarista: um caso de descoordenação intergovernamental
}

\author{
Fernando Luiz Abrucio 1 \\ Eduardo José Grin 1 \\ Cibele Franzese 1 \\ Catarina lanni Segatto ${ }^{2}$ \\ Claúdio Gonçalves Couto ${ }^{1}$ \\ 1 Fundação Getulio Vargas / Escola de Administração de Empresas de São Paulo, São Paulo / SP - Brasil \\ 2 Universidade Federal do ABC / Programa de Pós-Graduação em Políticas Públicas, São Bernardo / SP - Brasil
}

Este artigo analisa como o federalismo brasileiro tem afetado o combate à COVID-19. Tendo por base uma análise histórico-institucional do caso brasileiro, busca-se compreender como o modelo federativo construído pelo governo Bolsonaro influenciou as respostas ao combate da pandemia no país, bem como os resultados do confronto de dois modelos federativos nesse processo. De um lado, o ideário e as estruturas institucionais da Constituição de 1988 com características cooperativas e forte coordenação federal. De outro, o federalismo bolsonarista baseia-se numa visão dualista de relações intergovernamentais, com menor participação da União na redução de desigualdades territoriais e no apoio a governos subnacionais, além da postura centralizadora e hierárquica nas questões de impacto nacional. O estudo mostra que o federalismo bolsonarista aumentou o conflito com governos subnacionais e tem descoordenado políticas públicas de enfrentamento à pandemia. Conclui-se que as crises sanitária e federativa caminham juntas e trazem à tona uma questão chave: a importância da coordenação governamental nas políticas públicas de enfrentamento à pandemia.

Palavras-chave: COVID-19; federalismo; relações intergovernamentais; políticas públicas; governo Bolsonaro.

\section{Lucha contra la COVID-19 bajo el federalismo bolsonarista: un caso de descoordinación intergubernamental}

Este artículo analiza cómo el federalismo brasileño ha afectado la lucha contra la COVID-19. A partir de un análisis histórico-institucional del caso brasileño, buscamos comprender cómo el modelo federativo construido por el gobierno de Bolsonaro influyó en las respuestas para combatir la pandemia en el país, así como los resultados de la confrontación de dos modelos federativos en este proceso. Por un lado, el ideario y las estructuras institucionales de la Constitución de 1988 con características cooperativas y una fuerte coordinación federal. Por otro, el federalismo bolsonarista que se basa en una visión dualista de las relaciones intergubernamentales, con menos participación del Gobierno Federal en la reducción de las desigualdades territoriales y en el apoyo a los gobiernos subnacionales, además de la postura centralizadora y jerárquica en materias de impacto nacional. El estudio muestra que el federalismo bolsonarista ha aumentado el conflicto con los gobiernos subnacionales y ha descoordinado las políticas públicas de combate a la pandemia. Se concluye que las crisis sanitaria y federativa van juntas y plantean una cuestión clave: la importancia de la coordinación gubernamental en la implementación de políticas públicas de enfrentamiento a la pandemia y sus efectos sociales y económicos.

Palabras clave: COVID-19; federalismo; relaciones intergubernamentales; políticas públicas; gobierno Bolsonaro. 


\section{Combating COVID-19 under Bolsonaro's federalism: a case of intergovernmental incoordination}

This article analyzes how federalism has affected policy responses to the COVID-19 pandemic in Brazil. Through historical-institutional analysis, the study examines how the model of federalism adopted by President Bolsonaro's government influenced policy responses to the pandemic in the country. In addition, the research points out the existence of two models of federalism in the case analyzed, addressing the outcomes of the confrontation between them. The first model refers to ideas and institutional structures that have emerged since the 1988 Brazilian Federal Constitution with cooperative features and strong federal coordination. The second, named "Bolsonaro's federalism," is based on a dualistic view of intergovernmental relations with little participation of the federal government in reducing territorial inequalities and supporting subnational governments, while centralizing issues of national importance and adopting a hierarchical stance. The study shows that Bolsonaro's government increased the conflict with subnational governments and jeopardized the coordination of policy responses to the COVID-19 pandemic. We conclude that healthcare and federative crises go together and raise a key question: what is the importance of governmental coordination to implement policies to respond to the pandemic and its social and economic effects? Keywords: COVID-19; federalism; intergovernmental relations; public policies; Bolsonaro's government.

\section{INTRODUÇÃO}

O combate à atual pandemia tem sido afetado por diversos fatores. Um deles é o efeito da interligação entre atores políticos e o funcionamento institucional das políticas públicas. Neste campo, um aspecto recorrente na crise epidemiológica é a dimensão da territorial politics (Broscheck, Petersohn, \& Toubeau, 2017), que afeta federações e países com mecanismos federalizados (Baldi, 1999; Swenden, 2006).

O efeito da territorial politics ocorre em vários países, como Estados Unidos, Itália, Espanha, Alemanha, Índia, México e Brasil. Nestes países as relações de conflito e cooperação entre a esfera nacional e os governos subnacionais moldaram em boa medida políticas recentes de Saúde pública contra a COVID-19. Em algumas dessas experiências, soluções federativas bem-sucedidas explicam parte do êxito no combate à pandemia, como no caso alemão (Pleitgen, 2020). Nos casos norteamericano e brasileiro, ao contrário, houve dificuldades na luta contra a COVID-19, especialmente por conflitos e descoordenação intergovernamental.

Este artigo analisa como o federalismo afetou o combate à COVID-19 no Brasil sob a presidência de Bolsonaro. Busca-se mostrar que as relações intergovernamentais já estavam em processo de mudança antes desta crise, porém seus efeitos se intensificaram durante a pandemia, quando a necessidade de um papel coordenador da União ficou mais evidente. Isso porque crises sanitárias exigem forte coordenação governamental, sobretudo em países federativos, como mostra o trabalho de Paquet e Schertzer (2020), por meio do conceito de complex intergovernamental problem. Por esta razão, vem surgindo uma literatura que analisa como a questão territorial afeta as políticas de combate ao novo coronavírus (Organização de Cooperação e Desenvolvimento Econômico [OCDE], 2020; Ramirez de la Cruz, Grin, Sanabria-Pulido, Cravacuore, \& Orellana, 2020; Tulich, Rizzi, \& McGaughey, 2020).

O marco analítico apoia-se na relação entre atores, instituições, políticas públicas e federalismo (Pierson, 1995; Benz \& Broschek, 2013). Baseando-se nesse parâmetro geral, a análise da coordenação federativa no Governo Bolsonaro aponta que, no combate à COVID-19 no Brasil, houve um confronto de dois modelos federativos. De um lado, o ideário e as estruturas da Constituição de 1988 (CF/88), baseados em características cooperativas e forte coordenação federal. De outro, a concepção bolsonarista de federalismo, norteada por uma visão fortemente centralizadora e 
hierárquica sobre questões com impacto nacional e dualista em relações intergovernamentais, o que diminui a participação da União na redução de desigualdades territoriais e na ajuda a governos subnacionais.

Do exposto, três questões chave emergem: quais as propostas e as efetivas mudanças do federalismo sob Bolsonaro que foram intensificadas pela pandemia? Diante disso, quais as continuidades federativas e novas estratégias adotadas por governos subnacionais - especialmente estados - que fazem diferença no jogo federativo? Por fim, qual o impacto dessas relações intergovernamentais sobre as políticas públicas contra a COVID-19? Este último ponto é a principal contribuição do artigo ao campo da Administração Pública.

\section{PROCEDIMENTOS METODOLÓGICOS}

Este estudo baseia-se numa análise qualitativa e histórico-institucional que lida com duas temporalidades. A primeira refere-se aos trinta anos de relações intergovernamentais pós-1988 e tem como ponto de partida a sistematização da literatura já consolidada sobre o tema. A outra diz respeito ao processo em curso, no qual se busca mudar o padrão de distribuição do poder territorial nas políticas públicas e sua concretização específica no combate à COVID-19. Para compreender esse fenômeno inconcluso, selecionamos ideários e eventos críticos (Capoccia \& Kelemen, 2007) representativos da tentativa bolsonarista de alterar o federalismo brasileiro, bem como as reações a este modelo.

A discussão sobre a COVID-19 como evento crítico é a "linha de chegada" de uma análise segundo a qual o governo Bolsonaro tem buscado, desde o início, mudar relações intergovernamentais, processo que na pandemia tem sua forma mais intensa. Em termos contrafactuais: inexistindo a pandemia, não existiria esse confronto? Nossa resposta é não, pois ele já vem ocorrendo desde 2019, foi escalando o nível de enfrentamento e, com o surgimento da pandemia, esse acelera um processo em curso. Dada a complexidade do fenômeno sanitário, as consequências negativas do padrão intergovernamental bolsonarista se ampliam.

Realizou-se uma análise histórico-narrativa para embasar a leitura longitudinal, pois só é possível discutir o federalismo bolsonarista em contraste com o desenho institucional pós-1988, baseado no modelo cooperativo. Na análise da coordenação federativa durante a pandemia, optou-se pelo uso do process tracing, método qualitativo capaz de reconstruir uma sequência de eventos ainda em andamento (Beach \& Pederson, 2013). Assim, a narrativa de "falas conjunturais" e documentos constituem o recurso possível e necessário para analisar um fenômeno em curso, pois permite compreender o jogo federativo adotado pelos entes subnacionais e pelo governo federal.

Nessa linha, realizou-se uma análise documental (legislação e declarações de representantes do governo federal, de estados, municípios, do Congresso Nacional, Judiciário) e da cobertura da mídia, acompanhando os passos do governo Bolsonaro desde seu início, com um recorte especial para os primeiros meses da pandemia (fevereiro a junho de 2020). A referência aos conteúdos abordados na imprensa perderia fôlego analítico e capacidade explicativa sem a referência histórico-narrativa apresentada no Quadro 1, que apresenta a trajetória de medidas do governo federal antes e durante a pandemia. Todas as iniciativas são guiadas por uma mesma lógica de revisão do federalismo cooperativo derivado da CF/1988. 

(ATÉ JUNHO DE 2020)

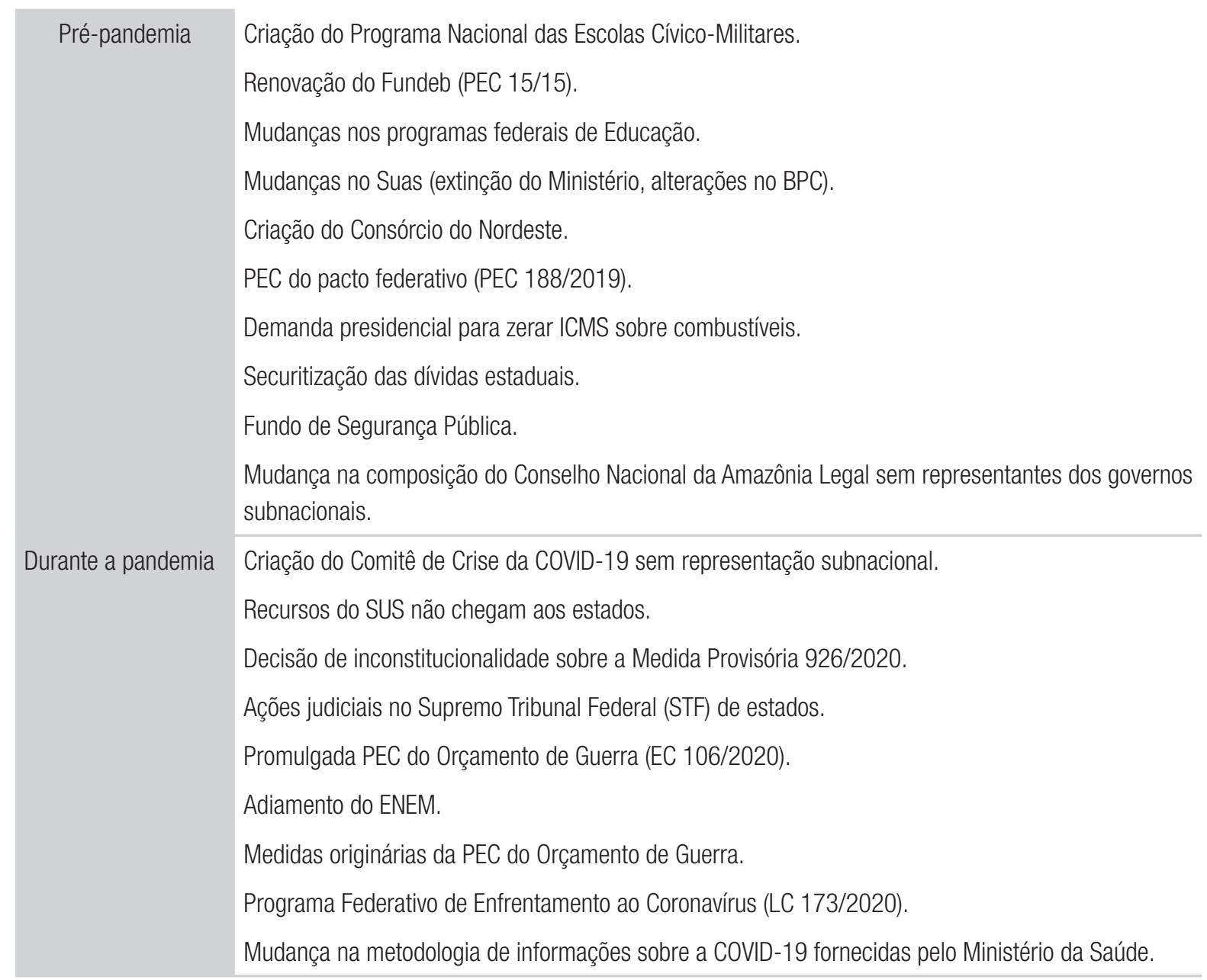

Fonte: Elaborado pelos autores.

\section{MODELOS DE FEDERALISMO E COORDENAÇÃO INTERGOVERNAMENTAL}

No estudo das políticas públicas no federalismo, a coordenação intergovernamental é fundamental, pois não é fácil compatibilizar a convivência entre autonomia e interdependência, que marca as federações e seu processo decisório (Pierson, 1995). Aqui, há dois tipos ideais em confronto: os modelos dual e cooperativo.

No federalismo dual, supõe-se que cada ente possua autonomia constitucional estrita sobre diferentes áreas para impedir a centralização do poder (Loughlin, Kincaid, \& Sweden, 2013). Seu pressuposto é que governos locais gastam mais eficientemente, são mais accountable para suas populações e políticas públicas, respondem melhor a particularidades locais. A coordenação federativa seria contingente, circunstancial e, no limite, desnecessária, por ser prejudicial à eficiência decisória e à alocação de recursos. 
Hoje, o caso paradigmático de federalismo dual são os EUA. Após décadas de crescimento de um modelo mais colaborativo (1930 a 1980), o presidente Reagan mudou a rota federativa, descentralizando funções dos estados (devolution powers), bem como reduzindo a participação da União no apoio e na articulação federativa. Esse padrão dualista tornou-se hegemônico, gerando aumento da desigualdade e da competição interestadual (Kettl, 2020).

No modelo cooperativo, a autoridade compartilhada combina autonomia subnacional com coordenação nacional. Sua disseminação ocorreu com a expansão do Welfare State após a Segunda Guerra Mundial (Obinger, Leibfried, \& Castles, 2005). Para garantir direitos universais, federações combinaram processos centralizados (como financiamento, normatização e indução) com implementação descentralizada e autônoma de políticas públicas. Assim, o modelo cooperativo não contrapõe centralização e descentralização, trata-as como combinação e não como oposição (Broschek, Petersohn, \& Toubeau, 2017).

Em vez de dualismo, o que se exige é coordenação para compartilhar objetivos, de modo a reduzir duplicação, sobreposição e desigualdades territoriais. Esse processo envolve muitas vezes formas de participação e proteção dos governos subnacionais perante decisões federais, especialmente mediante fóruns intergovernamentais que minimizam e/ou impedem ações unilaterais atuando como federal safeguards (Schnabel, 2015). A crise da COVID-19 evidenciou a importância da coordenação intergovernamental para combater a pandemia (OCDE, 2020; Tulich, Rizzi, \& McGaughey, 2020). Porém, nos Estados Unidos, o governo Trump radicalizou o modelo dualista ao responsabilizar totalmente os estados, ou disputar protagonismo com eles. O avanço da doença foi avassalador. Essa atuação suscitou a ideia do "federalismo darwinista", que coloca entes uns contra os outros (Cook \& Diamond, 2020; Geltzer, 2020). Neste contexto, uma liderança nacional é essencial porque, conforme disse o governador de Nova York, Andrew Cuomo, "state boundaries mean very little to the vírus".

No Brasil, o enfrentamento à COVID-19 evidencia o confronto dessas duas concepções de federalismo. Opõem-se o modelo cooperativo, construído a partir da CF/88, e o projeto bolsonarista, similar ao dualismo trumpista, baseado no slogan "Mais Brasil, Menos Brasília", isto é, menos ação da União em políticas públicas.

\section{0 FEDERALISMO BRASILEIRO PÓS-1988: COMBINAÇÃO DE COORDENAÇÃO E AUTONOMIA}

A Federação brasileira, originariamente, inspirou-se no dualismo norte-americano. O desenho constitucional de 1891 propunha grande autonomia estadual, pouca intervenção da União e ausência de coordenação federativa (Abrucio, 1998). Com a chegada de Vargas ao poder, iniciou-se uma trajetória de grande transformação do federalismo, quando o papel da União cresceu continuamente, especialmente nos períodos autoritários do Estado Novo e do Regime Militar (Arretche, 2012). Esta centralização de poder enfraqueceu o federalismo e não redundou em cooperação, dado que os governos subnacionais foram afastados das principais decisões políticas e de políticas públicas.

A redemocratização alterou o modelo federativo anterior, dando maior autonomia política, administrativa e financeira a estados e municípios. Contudo, essa descentralização foi contrabalançada por políticas nacionais em prol da expansão de políticas públicas e do combate à desigualdade. Assim, coube à União importante papel de coordenação federativa, mediante normatização, indução e financiamento (Abrucio, 2005; Arretche, 2012). A implementação ficou a cargo dos governos subnacionais, tornando-os centrais na expansão das políticas de welfare (Grin \& Abrucio, 2018).

REVISta de AdMinistração PÚblica | Rio de Janeiro 54(4):663-677, jul. - ago. 2020 
O arranjo federativo pós-1988 exigiu equilibrar objetivos nacionais de welfare com sua implementação descentralizada e autônoma. Para tanto, a criação de sistemas de políticas públicas garantiu também a participação dos governos subnacionais no processo decisório federativo (Franzese, 2010). A cooperação federativa originada da $\mathrm{CF} / 88$ avançou incrementalmente, mas não teve trajetórias nem resultados similares em todas as áreas. Neste processo, todos os presidentes dialogaram com estados e municípios para fortalecer o pacto federativo e expandir políticas sociais.

$\mathrm{Na}$ área da Saúde, o caso mais paradigmático, o Sistema Único de Saúde (SUS), foi construído na década de 1990. O modelo apoiou-se em diretrizes nacionais relacionadas a normatização e redistribuição de recursos, implementação descentralizada e espaços institucionalizados de participação social e negociação intergovernamental (Franzese \& Abrucio, 2013). O SUS inspirou a construção do Sistema Único de Assistência Social (Suas) em 2005, também ancorado na participação social, redistribuição de recursos, fóruns federativos e serviços descentralizados e hierarquizados (Bichir, Simoni, \& Pereira, 2020).

$\mathrm{Na}$ Educação Básica, a CF/88 criou o conceito de regime de colaboração para lidar com a dualidade de provisão dos serviços e baixa cooperação intergovernamental (Abrucio, 2010). Mas a coordenação intergovernamental não ocorreu de imediato porque o apoio da União a governos subnacionais só ganhou força a partir de 1996, quando se estabeleceram parâmetros mínimos nacionais, redistribuição de recursos, monitoramento e avaliação de resultados (Segatto \& Abrucio, 2018). Todavia, a falta de fóruns federativos formais resultou num sistema de articulação mais frágil comparativamente ao da Saúde e da Assistência Social. Ainda assim, todas as gestões federais conversaram com a União Nacional dos Dirigentes Municipais de Educação (Undime) e o Conselho dos Secretários Estaduais de Educação (Consed).

A Federação brasileira ainda tem problemas de fragmentação, sobreposição, competição e fragilidade de cooperação em alguns setores e no plano territorial (Grin \& Abrucio, 2017). Só que, mesmo com esses problemas, ela vinha avançando no reforço da coordenação e cooperação intergovernamentais na provisão das políticas públicas. Esta transformação incremental e incompleta do federalismo brasileiro foi contestada pelo presidente Bolsonaro, que, desde a posse, visa instaurar um federalismo dualista similar ao vigente nos EUA. A eclosão da pandemia escancarou a proposta bolsonarista e exacerbou conflitos entre União e municípios e, principalmente, estados, aumentando a descoordenação intergovernamental.

\section{0 SENTIDO DO FEDERALISMO BOLSONARISTA: MARCHA E CONTRAMARCHA}

Bolsonaro foi eleito presidente com um discurso contra o sistema político e a "velha política". Como parlamentar colocou-se contra a redemocratização do país ao constantemente defender o regime militar, mesmo após eleito (Campos, 2019). Seu governo tem como principal adversário os ideais da $C F / 88$, principalmente a expansão da atividade governamental gerada pelo crescimento dos direitos de cidadania e os checks and balances reforçados pelo novo arcabouço constitucional. Seu projeto neopopulista defende uma democracia sem mediações ou fiscalização institucional das relações entre governante e povo (Urbinati, 2019).

O federalismo cooperativo, central na CF-88, também foi atingido pela visão bolsonarista com o slogan "Mais Brasil, Menos Brasília". Aparentemente vinculado à transferência de poder a quem o deve ter de direito, esse bordão alicerça uma visão de Estado que combina ultraliberalismo econômico 
com antiliberalismo político. O primeiro propõe redução drástica da intervenção governamental, secundarizando até mesmo a desigualdade; o segundo busca debilitar controles institucionais em nome de um presidencialismo imperial, aliado a uma postura schmittiana da política, que considera opositores inimigos a serem destruídos (Schmitt, 1992).

Baseado nesses fundamentos, Bolsonaro atuou segundo a lógica de um tripé federativo. O primeiro suporte diz respeito à divisão rígida de funções entre níveis de governo. Responsabilidades deveriam ser repassadas a estados e municípios concomitantemente à diminuição drástica de participação da União no financiamento e apoio à redução das desigualdades territoriais. O pressuposto é de que estados e municípios são mais eficientes nas decisões de alocação de recursos, assim a União deveria intervir minimamente. $\mathrm{O}$ resultado seria aumentar a desigualdade entre governos subnacionais na provisão de serviços.

O segundo pilar reforça o dualismo pelo lado da concentração autocrática nas mãos da União em decisões que afetam entes subnacionais. Há pouquíssimo espaço para diálogo, negociação ou participação subnacional em programas federais. Os exemplos são vários, mas o pior ocorre em relação à região amazônica: o conselho criado para cuidar desta questão excluiu governadores da região da estrutura de governança.

A concepção de federalismo bolsonarista também contempla, como último pilar, o confronto intergovernamental e a luta constante contra adversários reais ou imaginados. Mobiliza a lógica de guerra para atiçar seu eleitorado e marcar posição antissistema. Os maiores inimigos são as instituições e suas lideranças, pois sua visão do presidencialismo repudia a negociação institucional e os checks and balances do Estado brasileiro, entre os quais está o federalismo.

Seguindo essa lógica política, Bolsonaro confrontou a Federação por dois motivos. Primeiro, a recusa dos entes subnacionais a políticas do bolsonarismo. Como estados e municípios são os principais responsáveis pela implementação na área social, podem mudar o rumo das decisões tomadas em Brasília. Soma-se a isso a disputa da Presidência com prefeitos e, sobretudo, governadores, vistos como atores que podem mobilizar a opinião pública, o Congresso Nacional e o Supremo Tribunal Federal (STF) em disputas federativas, além de poderem se tornar competidores ou aliados dos maiores adversários eleitorais do presidente. Ao longo da pandemia, esse confronto federativo disseminou-se e os governos subnacionais produziram cartas de repúdio a decisões do governo federal.

A combinação de lógica federativa compartimentalizada, autocrática e confrontadora evidenciouse com a pandemia. Porém eventos críticos anteriores já realçavam essa lógica do federalismo bolsonarista em quatro importantes agendas. A primeira delas ocorre no campo das políticas públicas, nas quais se tentou desmantelar a dinâmica cooperativa formal e informal. Um exemplo contundente foi na educação, visto que o MEC desconsiderou posições dos entes subnacionais em temas como expansão das escolas cívico-militares, alfabetização ou ações em relação à COVID-19. Como resposta, prefeitos e governadores tomaram decisões desprezando propostas do governo federal.

Esse tipo de conflito federativo também ocorreu em outros setores. Na política ambiental da Amazônia, os governadores foram rechaçados. Na segurança pública, o Ministério da Justiça abandonou o Sistema Único de Segurança Pública (Susp), reduzindo a cooperação com estados (Lima \& Bueno, 2020). Na experiência mais dramática, o combate à pandemia da COVID-19, chocaram-se o modelo bolsonarista e o SUS.

O segundo evento crítico concerne à agenda legislativa, particularmente à "PEC do pacto federativo" (PEC 188, 2019). Ela se orienta pela tríade “desobrigar, desindexar e desvincular", e busca 
flexibilizar o orçamento devolvendo ao Congresso Nacional o protagonismo sobre decisões alocativas dos entes federativos. No entanto, a concepção de "Mais Brasil, Menos Brasília" reduz a importância da coordenação federativa e tende a ampliar a desigualdade regional. Trata-se de uma nova agenda, em que a junção entre federalismo e nação perde propósito.

Um terceiro evento crítico consistiu na mudança no posicionamento do STF ao julgar conflitos de competência entre União e governos subnacionais. Historicamente, a tendência é decidir em favor da União (Halberstam, 2008). Canello (2017) aponta que, da CF/88 até 2015, de 920 processos sobre conflitos intergovernamentais, $81 \%$ foram favoráveis à União e $13 \%$ favoráveis aos estados. Com Bolsonaro, entretanto, o STF tem decidido claramente em favor dos entes subnacionais. Na mais importante dessas decisões, o Supremo decidiu que União, estados e municípios têm competência concorrente para atuar em questões sanitárias e podem estabelecer medidas restritivas para combater a pandemia sem aval do governo federal.

Por fim, como elemento marcante de reação ao federalismo bolsonarista, o Fórum de Governadores e o Consórcio do Nordeste fortaleceram a cooperação horizontal e supriram lacunas deixadas pela União. A crise gerada pela pandemia da COVID-19 evidenciou a necessidade de maior colaboração e transformou essas arenas em contrapontos às iniciativas presidenciais, sobretudo porque os governadores foram mais aderentes ao isolamento social, em contraposição à omissão presidencial.

\section{COMBATE À COVID-19 E FEDERALISMO BOLSONARISTA: PARADIGMA DE DESCOORDENAÇÃO INTERGOVERNAMENTAL}

No combate à COVID-19, a lógica federativa bolsonarista ganhou feição mais dramática, pois a pandemia é um complex intergovernmental problem, exige ainda mais coordenação intergovernamental que políticas corriqueiras. Em vez de mudar de rota, o presidente Bolsonaro radicalizou sua proposta federativa. O modelo compartimentalizado, autocrático e de confronto se robusteceu, enquanto governos subnacionais, especialmente governadores, reagiram reafirmando a cooperação e a ativação do SUS como paradigma de governança sanitária. Contudo imperou a lógica de reduzir a coordenação federal.

O primeiro ponto a destacar é a divergência entre presidente da República e o Ministério da Saúde, culminando na exoneração do ministro Henrique Mandetta. Após o início da crise, o então titular da pasta imbuiu-se do papel de dirigente do SUS, enaltecendo-o. Demitido, escreveu o seguinte tuíte:

Acabo de ouvir do Presidente Jair Bolsonaro o aviso da minha demissão do Ministério da Saúde. Quero agradecer a oportunidade que me foi dada, de ser gerente do nosso SUS, de pôr de pé o projeto de melhoria da saúde dos brasileiros e de planejar o enfrentamento da pandemia do coronavírus, o grande desafio que o nosso sistema de saúde está por enfrentar [...]” (Grifo nosso).

O elogio de Mandetta ao SUS, por duas vezes, é significativo, pois o ex-ministro provém do setor privado da Saúde. Isso mostra como a polarização no governo pode ser vista não apenas em torno da dicotomia isolamento social versus retomada da economia, mas como resiliência dos arranjos institucionais criados com a CF/88 versus a nova dinâmica bolsonarista de federalismo. $\mathrm{Na}$ polarização entre Bolsonaro e Mandetta, evidenciaram-se duas visões de federalismo: a da $\mathrm{CF} / 88$, representada no SUS, e a nova visão, que combina devolution powers e autocratismo ao lidar com demandas subnacionais. 
Houve resiliência institucional, pois arranjos federativos ainda pesam, embora atualmente funcionem de maneira menos pactuada. O presidente do Conselho Estadual dos Secretários de Saúde (Conass) tem sido apartado das decisões do Ministério da Saúde. O protagonismo de Mandetta e o isolamento de seu sucessor, Nelson Teich, foram absolutos em um sistema baseado na pactuação intergovernamental. No início da pandemia, governadores e prefeitos afirmaram que recursos não chegavam, algo anormal para o SUS, considerando a longa trajetória de funcionamento da transferência fundo a fundo (Bertoni, 2020). A desarticulação federativa piorou com a chegada do ministro Teich. O representante do Conass, principal estrutura do SUS de diálogo e negociação federativa, sequer foi convidado a participar de sua posse (Conass, 2020).

A descoordenação intergovernamental no enfrentamento da COVID-19 aumentou com o conflito entre presidente e governadores, o que ficou explícito na decisão sobre o estabelecimento do isolamento social. Nesta questão, três fatores confluíram: 1) opção do projeto federativo bolsonarista pelos devolution powers; 2) arcabouço de regras da CF/88 e seu blend de cooperação e autonomia; 3) legado prévio de políticas públicas. Numa federação como a brasileira, com seu sistema político altamente consensual, tal discussão chegou ao STF.

Quanto à opção pelos devolution powers, Bolsonaro se desobrigou da ação de combate à COVID-19 e demorou a se pronunciar sobre o vírus. Desde o início preocupado com a economia, minimizou a gravidade da situação ao ver superdimensionado o poder destruidor do vírus (Vasconcelos, 2020). No caso de federações, essa omissão pode gerar preempção de políticas públicas: ação subnacional pioneira em determinada área que provocaria dificuldades de posterior ação federal em virtude da institucionalização da política no tempo (Pierson, 1995). Foi exatamente o que ocorreu na determinação do isolamento social, que acabou liderada pelos governadores.

A ação dos estados aumentou o tom de confronto no discurso do presidente, que disse "tem certos governadores que estão tomando medidas extremas, que não competem a eles, como fechar aeroportos, rodovias, shoppings e feiras". E segue provocativamente numa entrevista coletiva: “Tem um governo de Estado que só faltou declarar independência”. Como reação, os governadores criticaram fortemente a postura centralizadora e sem diálogo do governo federal em documentos assinados quase unanimemente (Soares, 2020).

Optando pelo confronto, Bolsonaro ameaçou flexibilizar as medidas de isolamento adotadas pelos governadores, mas foi desautorizado pelo STF em medida cautelar proposta pela Ordem dos Advogados do Brasil (OAB). A decisão baseou-se nas competências compartilhadas em Saúde (artigo 23 da $\mathrm{CF} / 88$ ), presentes no federalismo cooperativo subjacente à Constituição.

Quanto ao legado da política pública, a pandemia contrapôs dois modelos de federalismo. A Saúde é a área que melhor representa o arranjo institucional desejado pela CF/88 na articulação entre política pública e federalismo: cooperação, transferência de recursos fundo a fundo, universalização da atenção e gratuidade. Este legado é posto à prova pelo projeto bolsonarista de federalismo.

O Comitê de Crise da COVID-19, sem representação estadual e municipal, ilustra essa concepção de um federalismo dualista radicalizado com comando centralizado. Ao mesmo tempo, a reação dos governadores para sustentar suas iniciativas e defender o SUS é positiva para o federalismo. A pandemia acelerou e desnudou um jogo federativo que já estava em curso, cuja disputa organiza-se em torno dos modelos dualista e cooperativo.

O exemplo que melhor ilustra essa situação é a edição da LC 173 (2020), que "estabelece o Programa Federativo de Enfrentamento ao Coronavírus". O principal ponto da lei é flexibilizar alguns limites da 
Lei de Responsabilidade Fiscal (LRF), acrescidos àqueles já flexibilizados pelo próprio art. 65 da LRF para calamidade pública, e estabelecer critérios de distribuição de $\mathrm{R} \$ 60$ bilhões em transferências federais para estados e municípios ( $40 \%$ por taxa de incidência da doença e $60 \%$ por população). Dois pontos chamam atenção: a lei é de 27 de maio e apresenta um dispositivo que menciona impedimento ao auxílio pelo município ou estado que não renunciar à ação ajuizada contra a União solicitando auxílio financeiro relacionado ao coronavírus.

A data impressiona, pois apenas no final de maio a União decidiu organizar a distribuição de recursos. A demora se explica, pois foi necessário, primeiro, viabilizar a possibilidade de recursos extras - o que foi feito com a aprovação da Emenda Constitucional 106, de 07 de maio de 2020, a qual instituiu o chamado "orçamento de guerra". Fazê-lo por lei é outra surpresa, pois o SUS costuma decidir por meio de fóruns federativos compostos por membros do Executivo.

As Comissões Intergestores, desde a década de 1990, decidem sobre a distribuição de recursos por meio das normas operacionais básicas, emitidas pelo Ministério da Saúde. A aprovação por lei mostra o protagonismo do Congresso Nacional, uma vez que estados e municípios têm conseguido melhor comunicação no cenário atual. Outro ponto sobre as ações judiciais é que este fato revela não apenas a forma hierárquica com que a União enxerga as relações intergovernamentais, mas também evidencia como os repasses fundo a fundo do SUS realmente não estavam funcionando na lógica bolsonarista de devolution powers.

A redução conjuntural do papel da União aumentou a descoordenação intergovernamental e a desigualdade entre estados e municípios. O conflito intergovernamental dificultou a tomada de decisões nacionais, como normas sobre isolamento social, distribuição de recursos e equipamentos médicos. Nessa situação, o Consórcio do Nordeste e estados como São Paulo e Maranhão tomaram decisões que geram competição horizontal e vertical por escassos insumos para o combate à COVID-19. Mesmo no que se refere a outras políticas, como a econômica e a educacional, não ocorreram articulações federativas para atuar contra a pandemia.

\section{CONCLUSÃO}

O federalismo brasileiro mudou substancialmente nas últimas décadas. O final do Regime Militar e a $\mathrm{CF} / 88$ permitiram assentar as bases de uma federação democrática, descentralizada, participativa e mais cooperativa, que alteraram o padrão anterior autoritário e centralizado.

Porém, o caminho aberto pela lógica federativa bolsonarista desequilibrou os pilares da engenharia institucional que emergiram após 1988, com sua aposta num modelo dualista, autocrático e de confronto intergovernamental. As disputas entre o presidente e os governadores relacionadas à autoridade para determinar o isolamento social, por exemplo, evidenciam essa questão.

Como decorrência do projeto federalista bolsonarista, os efeitos negativos no combate à COVID-19 revelaram-se significativos. O ápice desse processo ocorreu quando o Ministério da Saúde acusou os estados de mentirem sobre o número de mortos pela pandemia, deixando de informar com a periodicidade anterior o número de vítimas e infectados, colocando sob suspeição todo o modelo cooperativo do SUS.

O confronto e a descoordenação intergovernamentais, provocados pela falta de liderança da União, geraram desperdício de recursos, sobreposição de ações, redução dos ganhos de escala oriundos da coordenação federativa e prejuízos à garantia dos direitos sociais construída ao longo dos anos. 
RAP | Combate à COVID-19 sob o federalismo bolsonarista: um caso de descoordenação intergovernamental

O fato é que esse desarranjo federativo foi uma das principais causas para os péssimos resultados alcançados em relação ao número de doentes e de mortos. São dados que colocam o país numa posição desconfortável no cenário internacional.

Entretanto, um cenário diferente pode emergir da crise sanitária: o aprendizado sobre a importância do federalismo cooperativo no país, não só no funcionamento cotidiano das políticas públicas, mas, sobretudo, nos momentos em que predominam situações de complex intergovernmental problem. O período pós-pandemia deve gerar situações muito complexas em termos de crise social e econômica, tendendo a reforçar ainda mais a importância da cooperação intergovernamental na Saúde, além de outras áreas, como Educação e Assistência Social, mobilizando-as na reconstrução da sociedade brasileira.

Se o país realmente aprenderá que preservar um federalismo cooperativo é essencial para evitar novos fracassos, ainda é uma questão em aberto. Mas o exemplo da descoordenação intergovernamental no enfrentamento da COVID-19 ficará registrado como uma triste página de nossa história. 


\section{REFERÊNCIAS}

Abrucio, F. L. (1998). Os Barões da Federação: os governadores e a redemocratização brasileira. São Paulo, SP: Editora Hucitec.

Abrucio, F. L. (2005). A coordenação Federativa no Brasil: a experiência do período FHC e os desafios do governo Lula. Revista de Sociologia e Política, 24, 41-67.

Abrucio, F. L. (2010). A dinâmica federativa da educação brasileira: diagnóstico e propostas de aperfeiçoamento. In R. P. O. Oliveira, \& W. Santana (Orgs.), Educação e federalismo no Brasil: combater as desigualdades, garantir a diversidade (pp. 39-70). Brasília, DF: UNESCO.

Agranoff, R. (2007). Intergovernmental Policy Management: cooperative practices in federal systems. In M. A. Pagano, \& R. Leonardi (Eds.), The dynamics of federalism in national and supranational political systems (pp. 248-285). New York, NY: Palgrave Macmillian.

Arretche, M. T. S. (2012). Democracia, federalismo e centralização no Brasil. Rio de Janeiro, RJ: Editora FGV.

Baldi, B. (1999, setembro). Beyond the FederalUnitary Dichotomy (Working Paper 99-7). Berkeley, CA: University of California, Berkeley. Recuperado de https://escholarship.org/uc/item/05b607ng

Beach, D., \& Pedersen, R. B. (2013). Process-Tracing Method. Foundations and Guidelines. Lansing, Michigan: University of Michigan Press.

Benz, A., \& Broschek, J. (2013). Federal Dynamics Continuity, Change, and the Varieties of Federalism. Oxford, UK: Oxford University Press.

Bertoni, E. (2020, 15 de abril). Os erros e acertos de Mandetta, em duas análises. Nexo Jornal. Recuperado de https://www.nexojornal.com. br/expresso/2020/04/15/Os-erros-e-acertos-deMandetta-na-Saúde-em-duas-análises

Bichir, R., Simoni, S., Jr., \& Pereira, G. (2020). Sistemas Nacionais de Políticas Públicas e seus efeitos na implementação: $O$ caso do Sistema único de Assistência Social (Suas). Revista Brasileira de Ciências Sociais, 35(102), e3510207. Recuperado de https://doi.org/10.1590/3510207/2020

Broschek, J., Peterson, B., \& Toubeau, S. (2017). Territorial Politics and Institutional Change: A
Comparative-Historical Analysis. Publius: The Journal of Federalism, 48(1), 1-25. https://doi. org/10.1093/publius/pjx059

Campos, J. P. (2019, 01 de novembro). Doze vezes em que Bolsonaro e seus filhos exaltaram e acenaram à ditadura. Veja. Recuperado de https://veja.abril.com. br/politica/doze-vezes-em-que-bolsonaro-e-seusfilhos-exaltaram-e-acenaram-a-ditadura/

Canello, J. (2017). Judicializando a federação? O Supremo Tribunal Federal e os atos normativos estaduais (Tese de Doutorado). Instituto de Estudos Sociais e Políticos, Universidade do Rio de Janeiro, RJ.

Capoccia, G., \& Kelemen, D. (2007). The Study of Critical Junctures: theory, narrative, and counterfactuals in historical institutionalism. World Politics, 59(3), 341-369.

Conselho Nacional de Secretários de Saúde. (2020, 17 de abril). Ministro Nelson Teich reforça a importância da gestão tripartite no SUS a telefonema a Alberto Beltrame. Recuperado de http://www.conass.org. $\mathrm{br} / \mathrm{ministro-teich-reforca-a-importancia-da-}$ gestao-tripartite-no-sus-em-telefonema-a-albertobeltrame-2/

Cook, N., \& Diamond, D. (2020, 31 de março). 'A Darwinian approach to federalism': States confront new reality under Trump. Recuperado de https:// www.politico.com/news/2020/03/31/governorstrump-coronavirus- 156875

Emenda Constitucional no 106, de 7 de maio de 2020. (2020). Emenda Constitucional $n^{\circ} 106$, de 7 de maio de 2020. Institui regime extraordinário fiscal, financeiro e de contratações para enfrentamento de calamidade pública nacional decorrente de pandemia. Brasília, DF. Recuperado de http://www. planalto.gov.br/ccivil_03/constituicao/emendas/ emc/emc106.htm

Franzese, C. (2010). Federalismo cooperativo no Brasil: da Constituição de 1988 à constituição dos sistemas de políticas públicas. São Paulo, SP: FGV EAESP.

Franzese, C., \& Abrucio, F. L. (2013). Efeitos recíprocos entre federalismo e políticas públicas: os casos dos sistemas de saúde, assistência social e de educação. In G. Hocman, \& C. A. P. Faria (Orgs.), Federalismo e políticas públicas no Brasil (pp. 363388). Rio de Janeiro, RJ: Editora Fiocruz. 
Geltzer, J. (2020, 08 de abril). Trump's coronafederalism'pits states against each other. It's a disaster. Washington Post. Recuperado de https://www. washingtonpost.com/outlook/2020/04/08/trumpcorona-federalism/

Grin, E. J., \& Abrucio, F. L. (2017). La cooperación intermunicipal en Brasil frente al espejo de la historia: antecedentes críticos y la dependencia de la trayectoria después de la creación de la Ley de los Consorcios Públicos. Revista Políticas Públicas, 10(2), 1-27.

Grin, E. J., \& Abrucio, F. L. (2018). Las capacidades estatales de los municipios brasileños en un contexto de descentralización de políticas. Reforma y Democracia, 70, 93-126.

Halberstam, D. Comparative federalism and the role of the Judiciary (2008). In: G. A. Caldeira, R. Daniel Kelemen, \& K. E. Whittington. (Eds.), The Oxford handbook of law and politics (pp. 142-164). Nova York, NY: Oxford University Press.

Kettl, D. (2020). The Divided States of Federalism: Why federalism doesn't work. Princeton, NJ: Princeton Uiversity Press.

Lei Complementar no 173, de 27 de maio de 2020. (2020). Estabelece o Programa Federativo de Enfrentamento ao Coronavírus SARS-CoV-2 (Covid-19), altera a Lei Complementar $n^{\circ} 101$, de 4 de maio de 2000, e dá outras providências. Brasília, DF. Recuperado de http://www.planalto.gov.br/ ccivil_03/leis/lcp/lcp173.htm

Lima, R. S, \& Bueno, S. (2020, 29 de abril). Homicídios pelo sétimo mês consecutivo no país. Recuperado de https://facesdaviolencia.blogfolha. uol.com.br/2020/04/29/homicidios-crescem-pelosetimo-mes-consecutivo-no-pais/

Loughlin, J., Kincaid, J., \& Sweden, W. (2013). Handbook of Regionalism \& Federalism. London, UK; New York, NY: Routledge Taylor; Francis Group.

Medida Provisória 926, de 2020. (2020). Altera a Lei $\mathrm{n}^{\circ} 13.979$, de 6 de fevereiro de 2020, para dispor sobre procedimentos para aquisição de bens, serviços e insumos destinados ao enfrentamento da emergência de saúde pública de importância internacional decorrente do coronavírus. Brasília, DF. Recuperado de https://www.congressonacional. leg.br/materias/medidas-provisorias/-/mpv/141144

Obinger, H., Leibfried, S., \& Castles, F. G. (2005). Federalism and the welfare state: new world and european experiences. Cambridge, UK: Cambridge University Press.

Organização para Cooperação e Desenvolvimento. (2020). The territorial impact of COVID-19: managing the crisis across levels of government. Recuperado de http://www.oecd.org/coronavirus/policy-responses/ the-territorial-impact-of-covid-19-managing-thecrisis-across-levels-of-government-d3e314e 1 /

Paquet, M., \& Schertzer, R. (2020). COVID-19 as a Complex Intergovernmental Problem. Canadian Journal of Political Science, 1-5. Recuperado de https://doi.org/10.1017/S0008423920000281

Pierson, P. (1995). Fragmented Welfare States: Federal Institutions and the Development of Social Policies. Governance: An International Journal of Policy and Administration, 8(4), 449-78.

Pleitgen, F. (2020, 16 de abril). What Trump could learn from Angela Merkel about dealing with coronavirus. Recuperado de https://edition.cnn. com/2020/04/16/europe/merkel-trump-germanyfederalism-analysis-intl/index.html

Proposta de Emenda à Constituição 15, de 2015. (2015). Altera a Constituição Federal para estabelecer critérios de distribuição da cota municipal do Imposto Sobre Operações Relativas à Circulação de Mercadorias e sobre Prestações de Serviços de Transporte Interestadual e Intermunicipal e de Comunicação (ICMS), para disciplinar a disponibilização de dados contábeis pelos entes federados, para tratar do planejamento na ordem social e para dispor sobre o Fundo de Manutenção e Desenvolvimento da Educação Básica e de Valorização dos Profissionais da Educação (Fundeb); altera o Ato das Disposições Constitucionais Transitórias; e dá outras providências. Brasília, DF. Recuperado de https://www.camara.leg.br/proposicoesWeb/ fichadetramitacao?idProposicao $=1198512$

Proposta de Emenda à Constituição 188, de 2019. (2019). Altera arts. $6^{\circ}, 18,20,29$-A, 37, 39, 48, 62, 68, $71,74,84,163,165,166,167,168,169,184,198,208$, 212, 213 e 239 da Constituição Federal e os arts. 35, 107,109 e 111do Ato das Disposições Constitucionais Transitórias; acrescenta à Constituição Federal 
os arts. 135-A, 163-A, 164-A, 167-A, 167-B, 168A e 245-A; acrescenta ao Ato das Disposições Constitucionais Transitórias os arts. 91-A, 115, 116 e 117; revoga dispositivos constitucionais e legais e dá outras providências. Brasília, DF. Recuperado de https://www25.senado.leg.br/web/atividade/ materias/-/materia/139704 Ramirez de La Cruz, E. E., Grin, E. J., Sanabria-Pulido, P., Cravacuore, D., \& Orellana, A. (2020, July-August). The Transaction Costs of the Governments' Response to the COVID-19 Emergency in Latin America. Public Administration Review, 80(4), pp. 683-695. Recuperado de https://onlinelibrary.wiley.com/doi/ epdf/10.1111/puar.13259

Schmitt, C. (1992). O Conceito do Político. Rio de Janeiro, RJ: Editora Vozes.

Schnabel, J. (2015). The intergovernmental safeguard's capacity to prevent opportunism: evidence from eight federation. In Proceedings of 2015 ECPR General Conference, Montreal, Canada.

Segatto, C. I., \& Abrucio, F. L. (2018). Os múltiplos papéis dos governos estaduais na política educacional brasileira: os casos do Ceará, Mato Grosso do Sul,
São Paulo e Pará. Revista de Administração Pública, 52(6), 1179-1193.

Soares, I. (2020, 20 de março). Bolsonaro critica governadores: 'Medidas extremas que não competem a eles'. Correio Braziliense. Recuperado de https:// www.correiobraziliense.com.br/app/noticia/ politica/2020/03/20/interna_politica,835548/ bolsonaro-critica-governadores-medidas-extremasque-nao-competem-eles.shtml

Tulich, T., Rizzi, M., \& McGaughey, F. (2020). Cooperative Federalism, Soft Governance and Hard Laws in Australia's State of Emergency. Recuperado de https://verfassungsblog.de/fighting-covid-19legal-powers-and-risks-australia/

Urbinati, N. (2019). Me the People: How Populism Transforms Democracy. Cambridge, Massachusets: Harvard University Press.

Vasconcelos, R. (2020, 02 de abril). Coronavirus: relembre o que Bolsonaro já falou sobre a pandemia. Recuperado de https://politica.estadao.com.br/ noticias/geral,coronavirus-o-que-bolsonaro-jafalou-ate-agora-sobre-a-pandemia,70003234776 


\section{Fernando Luiz Abrucio}

https://orcid.org/0000-0002-3883-9915

Doutor em Ciência Política; Professor na Escola de Administração de Empresas de São Paulo da Fundação Getulio Vargas (FGV EAESP). E-mail: fernando.abrucio@fgv.br

\section{Eduardo Jose Grin}

https://orcid.org/0000-0002-0488-8487

Doutor em Administração Pública e Governo; Professor na Escola de Administração de Empresas de São Paulo da Fundação Getulio Vargas (FGV EAESP). E-mail: eduardo.grin@fgv.br

\section{Cibele Franzese}

(1)

https://orcid.org/0000-0001-7441-2831

Doutora em Administração Pública e Governo; Professora na Escola de Administração de Empresas de São Paulo da Fundação Getulio Vargas (FGV EAESP). E-mail: cibele.franzese@fgv.br

\section{Catarina lanni Segatto}

https://orcid.org/0000-0002-5094-8225

Doutora em Administração Pública e Governo; Professora visitante no Programa de Pós-Graduação em Políticas Públicas da Universidade Federal do ABC (UFABC). E-mail: catarina.segatto@gmail.com

\section{Cláudio Gonçalves Couto}

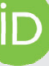

https://orcid.org/0000-0003-0153-1877

Doutor em Ciência Política; Professor na Escola de Administração de Empresas de São Paulo da Fundação Getulio Vargas (FGV EAESP). E-mail: claudio.couto@fgv.br 